\title{
on_education
}

Journal for Research and Debate

\section{lost and found among the aboriginal people of arnhem land, australia}

\author{
Bevlyne Sithole
}

I grew up at a time when my parents saw education as the only way out of poverty, while, in my later years, I understood it to be a means to escape culturally defined gender roles. Following independence, it was a way out of colonialism as the lawyers and teachers came back into the country and became leaders. Many Zimbabweans have now left the country to become academic tourists or, if they are lucky, they are academics in exile. It is here in the diaspora, in Northern Australia, where I start reflecting on being lost and found among the Aboriginal people.

Introduction

I grew up at a time when my parents saw education as the only way out of poverty, while, in my later years, I understood it to be a means to escape culturally defined gender roles. Following independence, it was a way out of colonialism as the lawyers and teachers came back into the country and became leaders. Many Zimbabweans have now left the country to become academic tourists or, if they are lucky, they are academics in exile. It is here in the diaspora, in Northern Australia, where I start reflecting on being lost and found among the Aboriginal people.

The idea to write about one's academic life challenges one to provide a candid self-portrait. This is not easy. What really constitutes an academic life and who defines it? Holborn Gray (2018) chooses to focus almost exclusively on the story of her life in academia. While Gray's academic life is focused and mostly plays out in academic institutions, mine does not. My academic life is one spent crisscrossing boundaries, sometimes inside, other times straddling them, but most of the time operating outside the boundaries (Sithole, 2017). It is important therefore to consider how far imposed boundaries or conventions in academia restrict or enable us.

In academia, one can believe in the refrain of "publish or perish", where one's identity becomes synonymous with citation indices or the number of pages on one's CV. The environment can be cutthroat and stressful. But, as Hagedorn (2012) notes, it is important to recognize that, for any academic, life and work are inextricably intertwined. Hagedorn makes some important distinctions between positive and negative academic lives and goes to some length to distinguish between them.

"The positive emeriti faculty were busy and felt productive. They kept a current identity and did not identify only as retired faculty but rather as consultants, highly sought experts, or as one person said a content grandparent. All felt that they continued to contribute, to have a purpose, and remained engaged." (Hagedorn, 2012, p. 488)

I use her framework to broadly consider and characterize my own academic life. At the end of the 
day, it truly is important to consider one's path when set against the broader goals of living a fulfilling life.

\section{The Aboriginal Context}

My professional experiences in Australia involve time spent working among and with Aboriginal people in Arnhem Land in the Northern Territory as a researcher, as a consultant and currently as an adjunct fellow of a university. My work has included leading and building the research capacity of members of the Aboriginal Research Practitioners' Network (ARPNet), which is a loosely coordinated group of community-based Aboriginal people who live in remote areas. Over the last ten years they have been trained to do participatory research and evaluations. Many of my observations reflect experiences from different projects that we have undertaken together. It is important to state that the development of the network was in response to a request from Aboriginal elders to build their capacity to be more effective and active in the research and evaluation space. What was interesting in the request was the clear differentiation that Aboriginal people wanted to make between them and the academics. The demand to be considered as research practitioners, rather than researchers, was a serious attempt to dissociate the members from the academics, not just because there was a difference concerning the level of education, but also because of the nature and the conduct of research itself. There is much context to that, including the negative attitudes that some Aboriginal people hold against academia (Smith, 1999; Henry et al., 2002; Fredricks, 2008).

There is considerably criticism in Australia about the manner in which research is conducted in remote communities. The indigenous reform agenda (Henry et al., 2002) argued for a reversal in the conduct of research in Aboriginal communities. That said, I would argue that what was, and still is, needed for that reversal to occur is a dramatic change in academia and in the mindset among academics about their superiority over a community member. Stated objectives and policies on engaging with communities are not always translated into real and positive practice and in most instances are just sugar-coating while maintaining the status quo. Smith (1999) focuses her attention on the way the colonial experience shapes and influences the way Academic continues to behave when researching Aboriginal people. She argues that Aboriginal people should reclaim the research space while pushing for the need to decolonize the conduct of research. Smith's arguments are persuasive and make the life of an academic more difficult because of the inherent and often unspoken tension that exists.

Over the years, together with community-based Aboriginal researchers from ARPNet, in order to carry out research the right way among Aboriginal people, we have developed and work to the mantra "one must be the right person, doing research in the right way, with the right people, at the right time, in the right spaces, using the right tools and for the right reasons". While appearing to be simple, this mantra underlines the complexity inherent in being an academic and researching in Aboriginal contexts and is therefore even more significant because the alignment of these requirements is so difficult.

The institutional contexts when working with Aboriginal people in Australia is well defined and elaborated in most organizations and educational institutions. Cruse (2001) argues that the regulation of activities among Aboriginal people is justified and necessary, given the history of interactions. While this may be so, the challenge is to know when regulation is enough and furthermore to be careful not to usurp the powers of the communities to self-determine. Aboriginal 
organizations and communities also have their own rules and protocols, which provide an additional layer of control. However, these are not always public as, in most communities, they are undocumented. One needs to be aware of and investigate the nature of these hidden, albeit highly important, requirements and protocols.

While affiliation to and membership in certain organizations requires you to observe the rules at an institutional level, the imperative to observe local rules and protocols is less clear. Adherence to local rules in fact becomes a matter of choice or dependent on the good manners of the academic. The requirement for academics to attend cultural awareness courses is intended to increase their sensitivity in this regard; but, once one observes university and government guidelines, there is less pressure to comply with local rules.

\section{Lost and found among Aboriginal people}

I have included some of the reflections, thoughts and questions that I have entertained; some include excerpts of conversations that I have had with my colleagues in ARPNet or Aboriginal elders and colleagues. These are a subset of issues and ideas that shape an academic when they are confronted by the complicated realities of Aboriginal societies, cultures and lifestyles. This is a genuine attempt to share my reality, rather than generalize or characterize my academic life experience as typical.

\section{Getting permission to undertake research}

The political ecology of academia in Australia is one that is characterized by multiple layering of checks and approvals, which complicate and, at times, alter the direction of academic pursuits. Transactional costs can be high, and one can become frustrated by the ethics process, especially when it seems to impact on academic license and/or freedoms. One's work goes through multiple gates and the path starts to become arduous and long. This clearly impacts on the number of academics prepared to do research work in remote communities. In the early stages, one's work is truly a negotiated product of these approval processes, as well as the committees that can make recommendations that are at odds with your philosophy and approach to undertaking research. Most importantly, they can also be at odds with what the communities on the ground want. The Godlike presence of the Ethics Committee looms large when one looks at the list of comments and the consequences of noncompliance. The ethics process seems to want to sanitize everything, with the respective panel reconstructing you into an academic it recognizes, as well as making comments on methodology that reflects what its members know, which may or may not necessarily be what Aboriginal people on the ground or you feel is the right way to do things. Adherence to a set standard or requirements, in order to conform to known and accepted practices, forces one into a box, which in turn restricts innovation, experimentation, and flexibility as one must comply and work to the agreed ethics approval document. We lose the possibility for experiencing excitement because of what I believe has become overregulation. Thus, I have spent my time alternating between reluctant compliance and musings about how I could reform such processes to more meaningfully empower the communities they protect.

The title of Martin's (2006) thesis, Knock Before You Enter, provides a clear and unequivocal direction to academics in terms of what to do when you are engaging with communities. One could perhaps ask the question as to whether anyone would even enter without knocking. Not likely in the case of Arnhem Land, as the controls on academic behavior are well articulated and defined. Processes are repeated, while it seems to me that, as new organizations with their own vetting 
requirements are created, one seems to spend so much time and effort being analyzed. The excitement with conducting research among Aboriginal people wanes as one considers the burdens and requirements of the process. Requirements for permission are present at every level. Projects are approved by ethics committees at various stages; and, sometimes, there is a requirement for multiple permissions. On other occasions, additional requirements are made even after one has completed the process. Consequently, while a project clearance may be decided by a national ethics body, one's affiliation may require institution-level clearance. Moreover, the competent Aboriginal body must also issue a permit, while local Aboriginal groups can be asked to give their approval too. Whose approval matters in these situations? At the ground level, you may have jumped through all the hoops before one of the traditional elders and the Djunkayi (land manager) say that they were not informed and want to give you their own clearance. So, the question is really about what constitutes enough clearance.

One important issue here is synchrony: how does one align one's schedules, methodological framework and client expectations to suit these multiple levels of checking and approval that one especially needs to do, as the ethics application normally occurs after one is funded on a project. How many delays does this process impose on a project and, more importantly, what is the cost of these delays to the project? The practice of ethics is required, even when the community is the source of the project and dictates the terms of engagement. The responsibility is still on the collaborating academic, not the community, to do all the paperwork. This requirement becomes confusing to Aboriginal people as it undermines their authority when their decisions are indirectly vetted and checked by a committee with which they have no relationship. On the ground, Aboriginal people believe that their permission overrides other forms of permission, but this is complicated by the fact that, within the community itself, one needs to consult and obtain permission from different individuals, who are not always in agreement on relevant issues. The question that arises here concerns whether committees in this position, by their requirements and actions, imply that communities can neither decide for themselves nor engage and collaborate with researchers on their own terms. A recent experience has demonstrated that academics can become pawns in power games between key stakeholders and are effectively powerless even when they have adhered to the rules.

\section{Working at the local level}

Gamarang Otto Bulmaniya Campion, one of my long-term collaborators and colleagues in ARPNet, was explaining to me the challenges faced by Aboriginal people when working with academics in his community. He called us outsiders. He said that we are middlemen who occupy a space between the community and the government; but, some of the people in that space like to behave as if they are the community. He used a story to explain what he meant.

An Aboriginal person could be walking down the aisle in a supermarket doing their shopping, and they have a clear idea about what they want to buy. But then a middleman arrives and offers to push the trolley for them. The Aboriginal person agrees to let them push the trolley and walks alongside the trolley to continue their shopping. Suddenly, they see the middleman start to put things in the trolley, possibly because they are buying something for themselves. The Aboriginal person thinks they better not ask the middleman what they are doing in case they might embarrass them. The Aboriginal person is even more surprised when the middleman pays for the shopping and so they raise their eyebrows and start to wonder what is going on. Then they walk to their motor car and they wonder some more when the middleman gives them all the shopping. At this point, the middleman says goodbye and the 
Aboriginal person is left with shopping they did not ask for nor in fact want. The middleman will go away and feel happy to have helped the Aboriginal person, even though they did not ask for the help, nor know what to do with all the help they got.

Clearly, Otto is talking about role capture by an academic, which he describes as blatant, opportunistic and unwelcome. In the most extreme cases, "taking over the trolley" manifests itself as "gatekeeping". As an academic, one has to be mindful and constantly vigilant in order not to become a gatekeeper. Aboriginal people distinguish between different categories of gatekeepers:

- those who are given the authority to speak for a community on a particular issue and know to acknowledge and cross-reference knowledge holders all the time;

- those who do not bother to get authority and use their "association (however long or short)" or "relationship" with the community as de facto permission to start speaking on its behalf and making decisions;

- those who are employed and forget their roles and start to take over decision-making, even though they are there to serve;

- and those Aboriginal people who have become elites and monopolize outsiders' interactions or attention and start to speak for and become de facto community leaders, even when they do not have the authority or permission to do so.

I consider the gatekeeper to be one of the great challenges in my work with Aboriginal people. I never know when they are speaking only for themselves or for the community; but, there have been times when I have witnessed "community capture" and wondered about the commitment to ethics. Long and Long (1992) caution against ignoring the effect that an actor can have on a community and how that can ultimately influence his or her work and dynamics. The story of the trolley, as told by Otto, explains how academics and other outsiders can lose their way.

One of the issues that complicates the relationship between academics and communities is "namegiving". Cultural practices and relationships among Aboriginal people impose some conditions on how you, as an academic, are viewed inside the Aboriginal community. You get what is called a "skin name" and suddenly you have a network of relationships spanning families, communities, clans and language groups. While this is important to Aboriginal people and defines their relations with and conduct towards you, as an academic, you are confronted by the significant opportunities and challenges this presents. Almost immediately, you become a part of the community, rather than an outsider, which undermines your notion about being an independent and unbiased actor. How does your "new skin name" affect sampling frameworks, for example? Once you are known by a skin name and your connections with particular groups are established, the ease with which you can crisscross boundaries becomes more limited. For example, you have "poison cousins", that is, people who you are not allowed to speak or be close to. This means that there are members in the community that you cannot directly interact with. Your gender becomes an issue: on some occasions, you become restricted to women's spaces, while other times you are not able to talk about certain issues because they are "men's business". Another matter is the fact that a "skin name" alone does not get you full entry into a community, as there are other requirements to access information, such as whether you have been initiated, attended a ceremony. While a skin name constrains one to a certain degree, it does place "more obligation" on the academic to be accountable and to undertake work that matters to one's adopted family. The academic is no longer a detached actor. In turn, some might ask how one is able to maintain objectivity and deal with bias. These are important questions and, over time, one finds ways to address these. 
Recently, I had an interesting experience where a reflective piece in a chapter, which referred to a conversation I had had with an elder, was highlighted during a quality assurance exercise for ethics purposes. Did I have permission to refer to a conversation that took place when I started working with Aboriginal people? The important issue here is not so much whether or not I had received permission, but rather under what conditions I had interacted with that elder. The question ignores the researcher's close connection with and the adoption by a family or clan. It maintains the illusion that an academic can only exist in one form, as opposed to the reality where the academic becomes molded by the setting and prevailing conditions as they undertake their work. As a member of the community, the process of ethical clearance is thus rendered irrelevant at some level, as Aboriginal people have their own procedures and protocols for giving permission, which one must observe if one wants to retain one's membership within a group. They also have their own "ways" to censure bad behavior if an adopted person misbehaves. In my experience, good behavior could be indicated by your interactions with the "Dreamings" (important totemic symbols) of the groups that one is working with. Stories about academics receiving warnings from Dreamings are common; for example, one's interactions with a king brown or other animals or natural phenomena like strong winds can be a sign that all is not well. Once a locust/grasshopper sat on my shoulder for a long while and, as I moved to swipe it off, one elder told me to stop, as that was his dreaming, giving him a message or commentary about our interaction. The query concerning whether or not there was clearance thus implies that every interaction that one has must be covered by ethical clearance. There seems to be an assumption that an academic only interacts with the Aboriginal people as an academic and not on any other level.

The meaning of silence

As a cheerful character, I have struggled with silence when being around Aboriginal people. Their silence and my subsequent acknowledgment of it through my own silence have been difficult. My early mentors used to gently slap my leg to remind me to listen when I felt the need to fill the silence and start talking. But, mostly, I had to consciously remember to be silent, to become comfortable in the silence, and to learn to read and decode the silence and the body language. These are new skills that were outside my experience and challenged the conventional wisdom of ideologies and methods, which tended to focus on and emphasize vocal communication and speech. At the start, it seemed to me that everything I knew and had learned was being put to the test. How does one communicate and record silence?

Existing methodologies and approaches in the social sciences emphasize the importance of exchanges where communication is vocal; and, while one worries about nuance, meaning and subtext, these are easy to deal with when one is familiar with the context. Dealing with silences was like learning a whole new language. Billian and Vemuri (2017) have analyzed the ethics of silence and used case studies to explore the different ways of looking at silence. The chances of misinterpretation and offence are much greater. While my experience of applying participatory methods in Africa and Indonesia were focused on getting people talking, I found Aboriginal communities to be a different matter. Not everyone can speak, not everyone has the right to speak, not everyone possesses the knowledge, not everyone has the right to share certain knowledge, and not all spaces are appropriate venues for sharing knowledge. While Participatory Rural Appraisal (PRA) and Participatory Action Research (PAR) training emphasized the importance of countering silence or disinterest and required the academic to have special facilitator skills, among Aboriginal people, this skill was redundant. Finding ways of decoding the silences challenges the tools that academics have and the capabilities they have. 
Silence was sometimes about defining rights and respecting the "right people speaking", while, on other occasions, it was an expression of disapproval of someone seeking to engage in the wrong place, at the wrong time and asking the wrong questions. There were even times when the reluctance to speak was about "shame" associated with the subject matter or wanting to minimize opportunities for "jealousing" within the community. Sometimes, silence can mean that one has posed questions to the wrong group. On a recent project, I understood that there was reluctance in the community to talk about cyclones as an expression of their recognition of the rights and responsibilities of one particular clan group that "owns the story and knowledge" about cyclones. Women speak on women's issues and this is called women's business, while men speak on men's business. The clear partitioning of knowledge spaces is respected and in a mixed focus group situation, silence can be seen as a reluctance to cross these spaces. Distinguishing between gender, age and ceremonial spaces is crucial in terms of how you treat or repeat knowledge.

\section{Sharing recognition}

I have been fascinated by the issue of sharing recognition since I started working with Aboriginal people because they are passionate and resolute about protecting their intellectual property. In some discussions, I have often asked them to explain what my intellectual property should be when we are working together. I used to think that I knew the answer, but I found this to be a difficult discussion, especially given the history of extractive and detached academics. There are many stories about researchers who have come and "behaved badly". With each story, I have listened carefully and tried to use it as an opportunity to learn and do things differently. There are different ways that Aboriginal people are acknowledged, most of which follow academic conventions, while there are others that break with those conventions. What is being recognized? Is what we are recognizing with regard to authorship enough? Perhaps the process should be broadened. Then, there is the issue of whether Aboriginal people want to be recognized and what their preference is.

On a project that I was involved with, I found that attitudes to knowledge are complicated. It is known who holds what knowledge and there are well-developed processes and protocols for transferring knowledge. When people talk about the intragenerational transfer of knowledge, it becomes clear that knowledge is acquired incrementally as one passes through one hoop to the next through a rigorous process. Holders of knowledge carefully choose to whom they pass on knowledge. This is in contrast with the research process, which demands knowledge sharing without the requisite checks and balances. Navigating the knowledge space in Aboriginal communities requires one to know and understand Aboriginal relationships and kinship structures and associated information.

In a discussion with one of the ARPNet members about collaborations on research projects, Dean Yibarbuk, he retorted that academic people should see Aboriginal people as more than just a human GPS. On further enquiry, Dean was clearly frustrated with roles Aboriginal people get given by academics and felt constrained to challenge the academics. Academics continue to define rules of engagement, but perhaps this dominance should be contested.

Castleden et al. (2010) write that rules specifying authorship were intended to protect, so that those who make significant contributions are not left out. The question concerns who defines what a significant contribution is and according to whose scale. Cherry Daniels, an elder and another colleague from ARPNet, declared quite unequivocally that Aboriginal people are researchers on their own lands who have been conducting research for a long time. One cannot argue with this type 
of pronouncement, as Aboriginal people are very knowledgeable about their societies and lands. This proclamation of an academic status has started to become validated through the award of honorary degrees across universities in Australia. While this is welcome, it challenges the conventions and standards of academia: are we readjusting and rewriting them to accommodate the new reality? Castleden et al. (2010) answers this question by stating that what might appear unorthodox nowadays may become the norm.

In some communities, the challenge for some old people is to find someone to pass on knowledge to. Some have started working with researchers to document their knowledge, recording and protecting it for posterity. But this has been contested by other members belonging to the same community who have argued that, while an individual might possess knowledge and have the authority to decide to whom they pass that knowledge, it belongs to the community; thus, any decision to transfer knowledge to an academic should necessarily be communal. This puts the academic at the center of community politics and highlights the complex nature of relationships on the ground. In one project, I found that communities are groups comprising multiple knowledge levels and competences; and, when they act to manage their lands, this knowledge all comes together when people are undertaking community action. This underscores the notion that knowledge learned can be applied communally.

\section{Conclusion}

Describing an academic life among the Aboriginal people of Arnhem Land, Australia, is like losing oneself, becoming overwhelmed and then finding oneself again. Being an academic among the Aboriginal people of Arnhem Land has really been a life-changing journey full of mistakes, questions and learning. Aboriginal communities, in common with many indigenous groups around the world, provide a specific set of conditions and spaces for an academic, most of them unfamiliar and unusual, where getting lost is the norm and finding oneself a rarity. Further, the constantly changing complex sociocultural setting complicates the nature of the interactions, especially when norms and practices are open to reinterpretation or sometimes misinterpretation. The learning continues, even as one becomes more reflective and familiar; and, just when one becomes "more comfortable" instead of becoming an authority, new challenges are thrown up and one begins again. It is this "constancy of challenge and curiosity" and "reinvention" that creates the energy that keeps one engaged.

Working with Aboriginal people has been a defining period in my academic life, in which I have been challenged so often in the way I conceptualize ideas, process and approaches. Many of the challenges have been both ideological and methodological and I have started to work on projects to develop tools that are "fit for purpose" among Aboriginal people. I have often wondered how much each solution to a challenge is a departure from conventions and standards that define academia, and whether it is the academic or academia itself that changes the most. My experience suggests that academia is slow to change and thus pits the changed academic against conventions and orthodoxy. At a recent conference, I was asked to present some of my work as an example of eight innovative projects being developed in the university. It would seem that academia is gradually opening up to emerging ideas, where the community is very much a part of defining future academia and academics. In the words of Hagedorn (2012), I have found my vocation and, by her definition, I am working towards becoming a positive academic.

\section{References}


Billias, N., \& Vemuri S. (2017). The Ethics of Silence. An Interdisciplinary Case Analysis Approach. London and New York: Palgrave Macmilan.

Castleden, H., Morgan, V. S., \& Neimanis, A. (2010). Researchers' Perspectives on Collective/Community Co-Authorship in Community-Based Participatory Indigenous Research. Journal of Empirical Research on Human Research Ethics, 5(4), 23-32.

Cruse, S. (2001). Encouraging research guidelines to be put into practice: an Aboriginal health research ethics committee in action. Kaurna Higher Education Journal, 7, 23-27.

Fredericks, B. (2008). Making an impact researching with Australian Aboriginal and Torres Strait Islander peoples. Studies in Learning Evaluation, Innovation and Development, 5(1), 24-33.

Hagedorn, L. S. (2012). The meaning of academic life. Review of Higher Education, 35(3), 485-512.

Henry, J., Dunbar, T., Arnott, A., Scrimgeour, M., Matthews, S., Murakami-Gold, L., \& Chamberlain, A. (2002). Indigenous Research Reform Agenda: Rethinking Research Methodologies. Linking Monograph Series: 2. Casuarina: Cooperative Research Centre for Aboriginal Health.

Holborn Gray, H. (2018). An Academic Life - A Memoir. Princeton University Press. Princeton and Oxford.

Long, N., \& Long, A. (Eds.). (1992). Battlefields of Knowledge: The Interlocking of Theory and Practice in Social Research and Development. Routledge: London and New York.

Martin, K. (2006). Please Knock Before You Enter: An Investigation of How Rainforest Aboriginal People Regulate Outsiders and the Implications for Western Research. (PhD thesis James Cook University, Australia). http://eprints.jcu.edu.au/4745

Sithole, B. (2012). The ARPNet Dilly Bag: A Practical Field Guide to Participatory and Other Research Tools for Use by Aboriginal Research Practitioners in Australia. ARPNet at RIEL, Charles Darwin University, Darwin.

Sithole, B. (2017). My knowledge, your knowledge, whose knowledge is it? Reflections from a researcher's journey through universities in North and South. In Adriansen, H. K., Madsen, L. M., \& Jensen, S. (Eds.), Higher Education and Capacity Building in Africa (pp. 171-192). London and New York: Routledge.

Smith, L. (1999). Decolonizing Methodologies Research and Indigenous Peoples. London: Zed Books. https://nycstandswithstandingrock.files.wordpress.com/2016/10/linda-tuhiwai-smith-decolonizing-m ethodologies-research-and-indigenous-peoples.pdf

\section{Recommended Citation}

Sithole, B. (2018). Lost and found among the Aboriginal people of Arnhem Land, Australia. On Education. Journal for Research and Debate, 1(3). https://doi.org/10.17899/on_ed.2018.3.7

\section{Download PDF version}

Do you want to comment on this article? Please send your reply to editors@oneducation.net. Replies will be processed like invited contributions. This means they will be assessed according to standard criteria of quality, relevance, and civility. Please make sure to follow editorial policies and formatting guidelines.

\section{bevlyne sithole}

Dr. Bev Sithole is an interdisciplinary scientist with a preference for working on grassroots 
issues in Aboriginal communities in Northern Australia. She is the research leader of the Aboriginal Research Practitioners' Network and her skin name given to her by the elders in the network is Ngaritjan. Her main interest is transformative process and methodology. 